OPEN ACCESS

Edited by: David Bueno,

University of Barcelona, Spain

Reviewed by:

Pei Sun,

Tsinghua University, China

Giovanna Bubbico,

G. d'Annunzio University of Chieti and

Pescara, Italy

*Correspondence:

Fernando Giraldez

fernando.giraldez@upf.edu

Specialty section:

This article was submitted to

Educational Psychology,

a section of the journal

Frontiers in Education

Received: 22 July 2019

Accepted: 19 December 2019

Published: 22 January 2020

Citation:

Giraldez F (2020) Teaching

Neuroscience as a Liberal Art.

Front. Educ. 4:158

doi: 10.3389/feduc.2019.00158

\section{Teaching Neuroscience as a Liberal Art}

\author{
Fernando Giraldez* \\ Departament de Ciencies Experimentals i de la Salut (CEXS), Universitat Pompeu Fabra de Barcelona (UPF at the Parc de \\ Recerca Biomèdica de Barcelona (PRBB)), Barcelona, Spain
}

This article describes a two-decade experience in teaching "Neurosciences for the Humanities: art, philosophy and the brain. "The course is a discussion about sensory physiology, knowledge, and the arts. The physiology of the senses provides interesting insights into how we get knowledge of the world and its reliability. This is a major topic in the philosophical tradition, which in turn leads to other interesting and timely questions such as what is science, belief, pseudoscience or post-truth. With respect to the arts, the course focuses on painting and music to discuss the perception of art, the neuroscience behind artistic innovations, les règles d'art and the idea of artists as intuitive neuroscientists. The course ends with a general discussion on "genes and culture," using the study of "critical periods" and brain plasticity to illustrate the complex interplay between "nature and nurture." The aim is at bringing a biological perspective to some classical "problems of the mind," but with full respect toward the philosophical and humanistic tradition. It is an opportunity to look at the work of great scientists, philosophers, painters, and musicians with another eyes, and to learn and enjoy the contributions of those giants of culture. An account of materials used in lectures, discussions and demos, as well as some examples of the teaching strategies are provided.

Keywords: perception, senses, mind, aesthetics, music, knowledge, nature vs. nurture

\section{INTRODUCTION}

\section{Neuroscience Beyond Neurosciences}

The quest for the mind has been a challenge for scientists, philosophers, and artists. Questions like the limits of human knowledge, the nature of aesthetic experience, or the nature/nurture problem are all "questions of thought," which are with us since the first records of human reflection. The scientific roots of art have also preoccupied great painters, sculptors or architects who explored physics and physiology, side by side with their artistic creations. And, likewise, remarkable scientists have been interested and inspired by philosophical questions and by art. This common interest is important to be transmitted in higher education in order to break the barriers among expertise fields, which have to do only in part with specialization, but also and more frequently with tradition or corporatism. The confrontation between science and humanities that is so prevalent in schools and universities is an upsetting false problem that hides the real dilemma between knowledge and ignorance. In the complex world in which our students will develop their professional lives it is crucial to have solid technical competence, as well as a wide-open mind that only culture can provide: a parsimonious scientific attitude along with a cultivated mind. 
It is frequent to try blending science and liberal arts through introductory courses of science for social sciences or humanities for scientists. This is probably fine and provides some mutual knowledge and understanding. It improves scientific and general culture of our students and helps understanding the diverse approaches and methods of the different disciplines. However, I believe that this may have also undesirably side effects, like reinforcing "expertise boundaries," or lead to too general overviews. One other interesting approach is to find spaces where scientific and cultural topics are discussed within a common playfield. This is what is meant by teaching science as a liberal art, to bring science to the field of ideas.

Neuroscience provides a wonderful opportunity to integrate knowledge from human and natural sciences. During the last decades, brain research has made important advances in offering new perspectives to some of the problems mentioned above. Perception, memory, emotions, development, or mental disease are topics that relate to the concept of "the mind." Our knowledge of the brain comes from studying different animals and it has a strong evolutionary perspective. This knowledge extends far beyond traditional medical domains like neurology or psychiatry, to impact also on other fields of knowledge like philosophy, art, economy, education, law, or gastronomy! The challenge is to find spaces where culture and neurosciences are discussed in equal terms, on common grounds.

\section{Neuroscience Humanities: Art, Philosophy, Brain}

\section{Aims and Scope of the Course}

The goal of the course is to show how the scientific knowledge of the brain revives classical questions in philosophy and art. And vice versa, how philosophers and artists have been exploring the brain and posing crucial scientific questions. This offers a good opportunity to re-examine the work of great thinkers and artists from different perspectives-besides an excellent excuse to read and look at masterpieces. As mentioned above, the alternative chosen here is to examine in some depth the neurophysiology of perception, and to link it to "cultural" questions. We want to link genes and neurons to Plato's Allegory of the Cave or Leonardo's sfumatto. In this course, the understanding of the synaptic organization of neurons in the visual cortex is as important as understanding the concept of form from an excerpt of Plato's dialogues. This is the scope, which is based on the work of several excellent neuroscientists, and also several art historians and philosophers. We walk on the shoulders of giants. The final goal is to make students of humanities and sciences reflect on the connection between science and ideas, and the importance of ideas for science.

There are also several other specific goals for the course, which is addressed to students with all backgrounds. First, to get them into the logics of the scientific knowledge of the brain. This aims to go beyond metaphorical interpretations of "the mind" and root mental activities on neurons and circuits, to understand its biology and its evolutionary logos. Secondly, to experience art from another perspective, to look at classic masterpieces with a "neuroscientific eye," finding unexpected ways of enjoying painting. Further on, to discuss about the rules of art, asking what makes beauty, or how much of our brain's rules step into our aesthetic experience. Finally, the third major goal is to discuss the constraints that our brain physiology sets to our knowledge, the nature of science and belief, and the reliability of our ideas. This drives us into classical philosophy and the discussion of post-truth or pseudoscience.

Art is present in the course with classic painting, from Medieval to the Baroque, with some notes on contemporary artistic movements. Music is also present with examples of classical and popular music. Philosophy in the course is broadly speaking "the question of knowledge," from Plato to Russell, a selection rather than an overview. And finally, there is a section that deals with the nature/nurture question, formulated as "genes and culture." The course is "Eurocentric," even more, Spanishcentered. For foreign students this provides a component of knowing more about Spanish culture. For Spanish students it has the advantage of familiarity. But this is rather a disclosure, a humble confession of author's limitations, the strategy of the course being easily adapted to different cultural contexts.

An evolutionary and scientific perspective on art or philosophy is far from any scientific supremacy. On the contrary, the spirit of the course is to bring scientific knowledge to current thought, like most great philosophers did in the past. As discussed below, the exploration of the biological roots of art does not at all undermine the cultural or historical aspects of art. Further, it is also important to tune down some overuse of neurosciences for "explaining everything," the use of neuroscience as the only level of explanation. The overstatement of neurosciences can be seen frequently in the misuse of brain imaging data or genetic studies. The prefix neuro- has become a fashion that too frequently ideological views of society wrapped with scientific terminology (Newman, 2017). Therefore, one important aspect in the course is to discuss about the limits of our current knowledge of the brain and to provide our students with reliable assessment criteria.

There are many common places on brain function and human physiology that conform a "folk psychology" with which students arrive to the course, independently of their academic background. I like to check student's ideas on some specific problems by passing a "First-day Questionnaire" (Supplementary Material 1), which calls them to comment on a couple of questions. The questionnaire is full of traps, pointing to "generally accepted ideas," including the $10 \%$ myth, for instance. This test is never intended to be an exam or even less a judgment on opinions. It provides the instructor with information on the background of accepted ideas, and it is also used as a selfassessment for the students, since they have it back on the last day of the course.

One notion that permeates the course is that "it makes no sense to distinguish between aspects of behavior that are 'biological' and those that would be described as 'psychological"' (Sapolsky, 2017). The biology of the brain provides knowledge about ourselves, useful knowledge about the human condition. It is also important to stress that if we have not yet a good neurophysiological explanation for a phenomenon, it does not mean that science claims that it does not exist, but that there is no 
explanation. And its corollary: the lack of a scientific explanation does not imply that we need non-scientific explanations.

The following is a brief account of the topics discussed in the course, which are developed typically in 2 -h sessions, sharing lectures, seminars, and flipped-class type sessions. The first sessions tend to be more expositive using $50 \mathrm{~min}$ for a talk and then another $50 \mathrm{~min}$ for a discussion seminar where we solve problems or carry on demonstrations using on line materials. Thereafter, sessions become more active and they may start with a discussion on a problem or a general question, to then formalize the ideas with a short talk (see final comment on methods). The syllabus and details on course requirements and organization can be found in Supplementary Material 2.

\section{The Representation of the World}

"In order to cry, steer the imagination toward yourself, and if this proves impossible owing to having contracted the habit of believing in the exterior world, think of a duck covered with ants, or of those gulfs in the Strait of Magellan into which no one sails ever." Instructions on How to Cry, Cronopios y Famas, by Julio Cortázar.

The course starts with a general introduction to sensation and perception that goes from the neurophysiology of sensory receptors to the brain. Concepts like sensory transduction, sensory modality, distortion, lateral inhibition, along with ideas like bottom-up, and top-down processing make the core of our current understanding of perception. Just setting some of these questions in a broad context leads to a row of fundamental philosophical questions like "the inverse optics problem” discussed by Berkely (Purves et al., 2014), or Hanna Arendt's ideas on being and appearance: "the diversity (in appearances) is matched by the diverseness of sense organs among animal species, so what appears to living creatures assumes the greatest variety of form and shape: every animal species lives in a world of its own (Arendt, 1981)." But this is to provoke some unrest in the solid certainty of students on their senses, and to open some philosophical appetite. Before raising these discussions, we first explore the senses in some depth, as a long interlude before returning to philosophy.

\section{Vision and Art: The Retina}

Vision is perhaps one of the best explored areas of neuroscience, a window to the brain. As such, it drove the attention of scientists like Cajal, Hartline, Kuffler, Mountcastle, or Hubel and Wiesel to mention only few of the giants that made fundamental discoveries in this field. This teaching block reviews the physiology of vision to discuss their impact on the way we perceive art.

"From the retina to the brain" is a discussion on the processing of the visual information that occurs already in the retina, "retinal photoshoping." It includes the different properties of cone and rod photoreceptors and, more generally, foveal (central), and peripheral vision. And this leads to the earliest appearance of art in the course, which is no other than Margaret Livingstone's analysis on the smile of Mona Lisa (Livingstone, 2000). This is based on the illusion of movement created when we shift the corner of Gioconda's lips from foveal to peripheral vision.
One other example is Leonardo's sfumatto, a trick to our brain to suggest that the image is always in the peripheral retina, a way of making us doubt about its stillness. The opposite is used by Botticelli, whose idealized representations come from the intuitive understanding of the receptive fields of retinal ganglion cells (see below).

The center-surround organization of retinal ganglion cells is a particular case of "lateral-inhibition," the principle by which activation of a sensory neuron leads to inhibition of its neighbors. This results in sharpening the signal coming from a stimulus, and the consequent enhanced detection and discrimination. As applied to vision, it accounts for two interesting properties: the context-dependent computation of luminance and our ability to extract contours when there are no more that differences in luminance. The retina sends to the brain a description of a visual scene where edges are exaggerated and this is used by the brain to build up abstract versions of real objects. This is what Botticelli discovered in his idealized drawings like the The birth of Venus. Since one of the multiple versions of the visual image that the retina sends to the brain is that of computed edges, "we have inside us" an idealized description of the contours of the visual world (contours that do not exist in the real world). And this is what Botticelli provides to the brain, an all-foveal, high resolution, edge-enhanced version of a face: the power of line drawing (Sayim and Cavanagh, 2011).

But of course, this is not the only representation of the visual world that the retina sends to the brain. Following another general principle of brain function, the retina sends several parallel descriptions of the visual image. Depending on resolution, photoreceptor absorbance (spectral preference), the polarity of the response to light (excitatory or inhibitory, ON or OFF neurons), dynamics (transient vs. sustained responses), the retina sends up to twenty different descriptions of the visual image. Those are multiple versions of the visual picture, for instance "how green and rapid," overlapped with "how red and detailed..." etc. In the examples above, Boticelli or Leonardo make their artistic gesture by selectively biasing toward those partial parallel descriptions. They emphasize some of them against the others.

The above can be called "bottom-up" processing, the analysis and decomposition of a visual object into elementary descriptions. But now it is the problem of the brain to handle these multiple descriptions and convert them into our cohesive experience of the world. Here is where "top-down" processing comes to work.

\section{The Forms in the Brain: Brain Categorization}

"We can now begin to see that there is a straightforward relationship between the Platonic Ideal and the brain-based concept of constancies.... the Platonic Ideal of a face is what is common to all faces; it is in fact the brain's stored record" (Zeki, 1997).

From the retina we go to the brain, to describe the visual areas of the brain. The analysis of the primary visual cortex by Hubel and Wiesel provided one major breakthrough in neuroscience, and is discussed with some detail. Students learn what are simple and complex cells, as well as the columnar organization of the 
primary visual cortex. The decomposed the visual field into small dots of activity is reconstructed in the visual cortex into lines. The primary visual cortex (V1) contains a modular recognition system for all possible positions and orientations of a line in the visual space (Kandel et al., 2012). The major and deep principle disclosed by Hubel and Wiesel work is that there are neurons in the brain that are ready to extract specific features, they are feature detectors. In other words, we have neurons that are "waiting for" certain regularities to occur. They extract patterns with a intrinsic machinery that is there before the events happen, which frames the events when they happen. This is almost the definition of an a priori of the mind. This, along with other contributions led Hubel and Wiesel to be awarded with the Nobel Prize in Physiology and Medicine in 1981. The brain turns to be Kantian, if not Platonic as discussed by Zeki (1997) and Zeki (2018).

For many years, it was believed that visual processing was carried out solely by the occipital areas of the brain, where retinal-geniculate projections end. However, the exploration of other regions and the development of brain imaging techniques allowed the identification of several other cortical areas that specifically process visual information (Zeki, 1999). Information flows from the primary visual cortex to diverge and to be remapped into perhaps more than 30 different areas that perform specific operations on visual information. Parallel processing of visual information is illustrated by the differential effects of localized neurological injuries. Visual processing is also described as organized in two main streams of information, the "What" and the "Where" streams devoted mainly to contours, shapes, colors, object identification the former, and location, depth, orientation and movement the later. This is a gross approximation, that is currently used in neurological jargon.

The description of simple and complex cells leads to the question of whether or not may be high order feature detectors, like geometric figures, or why not "things" represented in the brain? This is the place to analyze the physiology of face perception, "face cells" and the organization of the infra-temporal cortex (IT). Study of single and aggregate neuronal activity from the IT cortex has shown a sophisticated system for feature detection, which extends beyond faces to multiple natural and human made objects. The IT holds a complex system for the categorization of the world that is stereotypically organized. This responds to a major function of the brain, which is to immobilize a constantly changing world in categories that can be handled and allow an adequate reaction. That is the problem of a zebra trotting in the fields, when she needs to identify a tiger within the yellow-ocher vegetation of the savanna. In the zebra's brain, the tiger has to be invariant to size, color, texture, light, etc. The ability to categorize the world is a formidable achievement for survival. This "irresistible attraction" for categorization has been exploited by painters as part of their characteristic style, their language. Two seemingly unrelated examples are discussed here, Bosch and Pollock (Figure 1). Bosch paintings (The Garden of Earthly Delights) are typically full of objects of different sizes, shapes and colors. This results in us being driven to move our eyes around the painting without a break, to keep looking and searching in order to identify the infinite objects that are in the picture. Seemingly paradoxical, the abstract painter Jackson Pollock (see Autumn Rhythm Number 30, https://www. metmuseum.org/toah/works-of-art/57.92/) uses the same neural machinery, and with a similar purpose. Pollock paintings are fully drawn, using lines with different patterns, sometimes with some regularity, others without it. He provides us with hints to find "something" in de canvas, suggestions to identify "what is in there." But he delivers nothing, he draws "no thing." So we keep searching and searching with no success. In both cases, our brain spontaneously looks for features to fit with our "object recognition system," to match events with our categorization machinery (see Kandel, 2016). With Bosch the search is never ending, because there are many things, with Pollock it is also never ending, but it is because there are none!

\section{The Construction of Color}

Although the retina is good in exaggerating contrast using lateral inhibition, this requires a minimal difference in luminance to be amplified, and in its absence we are blind to objects. Here is where color vision evolved with photo-detection enabling to compute wavelength contrast with the minimal or no energy contrast. Objects may reflect the same energy but rarely reflect the same wavelength composition as its background. This makes chromatic contrast a major tool for object identification (Wolfe et al., 2017). Color has interesting features like not changing under different viewpoints, or remaining constant under a wide range of illuminations. This is called color constancy an interesting phenomenon that relates to the particular organization of the connections between photoreceptors and retinal ganglion cells using again an opposing principle that result in color-opposing neurons. The unique combinations of color channels are described by the "opponent-process theory" of color vision (Hering). Color perception results from the activity of two opponent systems: a blue-yellow and a redgreen mechanism, rather than from mixing the activity of the different photoreceptors. Classical works of art use these oppositions, which can be observed in medieval miniatures or in Greco's paintings.

But color processing brings also other unexpected tools for painters. As mentioned above, color and position/movement are processed independently in different regions of the brain (never take that verbatim). But because of the evolutionary origin of this task-streaming, processing of position and movement is essentially color-blind, relying only on luminance differences between object and background. Therefore, if you provide the brain with color contrast without luminance contrast, the effect will be that the brain "knows" that there is something there, but it will be unable to accurately place the object in the visual field. This makes the object unstable, i.e., like in movement. The intuition for this mechanism is seen in Monet's Impression, soleil levant, the founding painting of Impressionism, so beautifully analyzed by Livingstone (2002). Monet paints a red sun with reflections on the water in the port of Le Havre, but all contrast resides in color, since the sun is equiluminant with the sky, and the reflections with the water (try it yourself by desaturating the picture, you will see that the sun and the reflections practically disappear). 


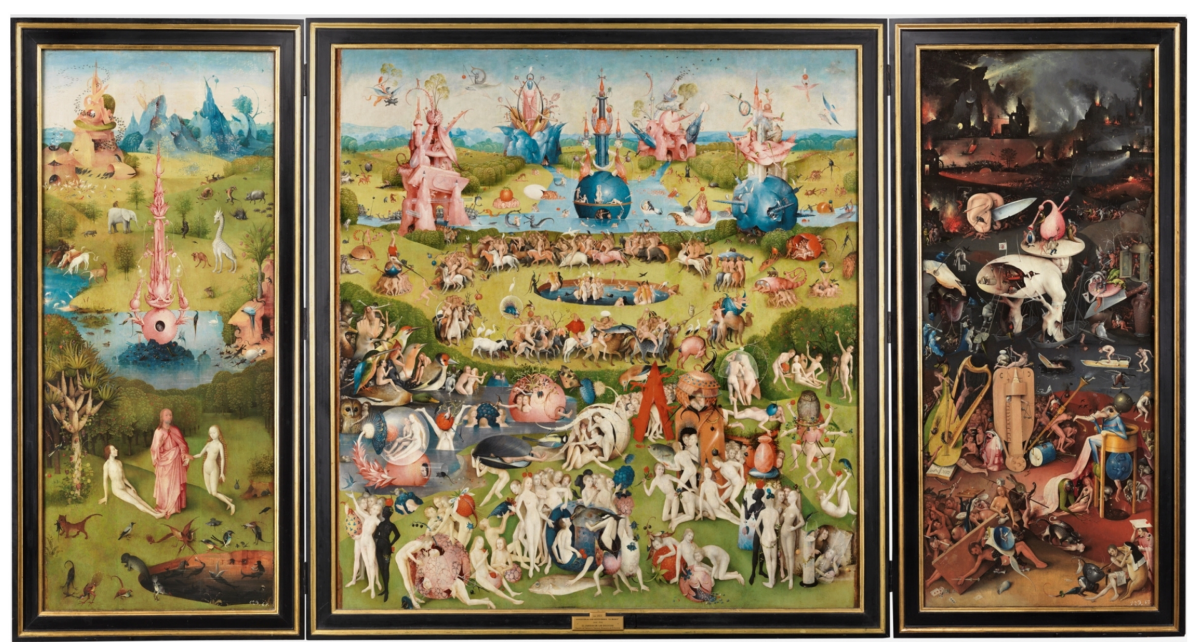

FIGURE 1 | Brain categorization as an artistic tool. Upper: Hieronymus Bosch, The Garden of Earthly Delights, oil on oak panels, Museo del Prado, Madrid.

Other "Monets" show even better this effect, like "The poppy field, near Argeneuil," or the "Les nymphéa" ("The lily pads"). This principle is also illustrated by the fascinating Kitaota's illusions http://www.ritsumei.ac.jp/ akitaoka/index-e.html.

\section{The Construction of Space}

Classical painting has one major and same problem as the brain: to convey a 3-D world from a flat surface (Figure 2). The 3-D world is projected onto the retina, which generates an internal description of the local variations in light. With this description, the brain generates our 3-D experience of the outside world and our "sensation" of a tridimensional world. But, the retinal projection is 2-D! Therefore, the brain uses some intrinsic mechanisms that allow the reconstruction of 3$\mathrm{D}$ out of 2-D data. And this is exactly the symmetric problem faced by painters who along centuries searched to represent a tridimensional world on a $2-\mathrm{D}$ canvas so that it evokes in us a 3-D sensation.

The brain uses one trick to generate the crispy sensation of 3-D and this is binocularity. It is based in the disparity between the two eyes due to their eccentric position, their different point of view. This disparity can be computed by specific neurons in the brain, the binocular disparity neurons, which give a measure of the different point of view of each eye. We experiment that in the class using anaglyph (filter color) glasses to experiment binocularity. Binocularity can be fooled providing different images to each eye. This generates the socalled binocular rivalry, which gives a disturbing feeling about consciousness, and an interesting view on perception.

But painters cannot use binocularity because a canvas is a 2-D surface, and there is no difference in looking at it with one eye or the other. Therefore, they need to use other tricks, which discovery has been a central part in the development of pictorial techniques. Vision can maintain a good degree of 3-D sensation just with one eye, using monocular cues (try to close one eye and the world is still 3-D, not so crispy, but still 3-D).
Painters have been exploring those cues to create the illusion of space (see Livingstone and Conway, 2005). The examination of monocular cues and the laws of geometric projection take us to a trip throughout the history of painting, from Byzantine and Gothic art to the Baroque. And this is the moment in which students focus on the pictorial revolution of the Renaissance, the principles of perspective, and the use of size, interposition, shadows, blurriness, aerial perspective, etc. to bring volume out of a canvas. The end of this trip-so to speak-is the tryumph of the Baroque. There are infinite examples to illustrate monocular cues, but I select only few of a number of great masters starting from the late medieval frescoes of Catalan Romanesque churches, Italian masters Duccio Buoninsegna, Simone Martini, or Giotto, to continue with Piero della Francesca, Fra Angelico, Botticelli, Leonardo as examples of early Renaissance. We then reach the Early Baroque with Caravaggio to then finish with Velazquez and Rembrandt. I also comment on the work of some late XIX Spanish painters Ramón Casas and Joaquín Sorolla. This selection is overtly biased to Spanish culture, but it can be tuned to any other context (Supplementary Material 3).

At this moment in the course, we plan a visit to the Fine Arts Museum. We are lucky in Barcelona, because the Museu Nacional d'Art de Catalunya, MNAC, is a wonderful space to illustrate most of the above ideas. The collection holds excellent pieces of classical painting from the unique Romanesque frescoes of the chapels in the Camino de Santiago in the Pyrenees, to a small but very fine collection of Renaissance and Baroque Spanish works, besides a good representation of modern and contemporary art. I like to make the visit accompanied by a colleague from the school of Arts and Humanities, making the visit far more appealing and bringing meaning where we just put rules.

\section{The Discussion on "les regles d'art" and Aesthetic Universals}

The rules of perception analyzed above lead to the discussion of the rules of art, a connection that has been explored 

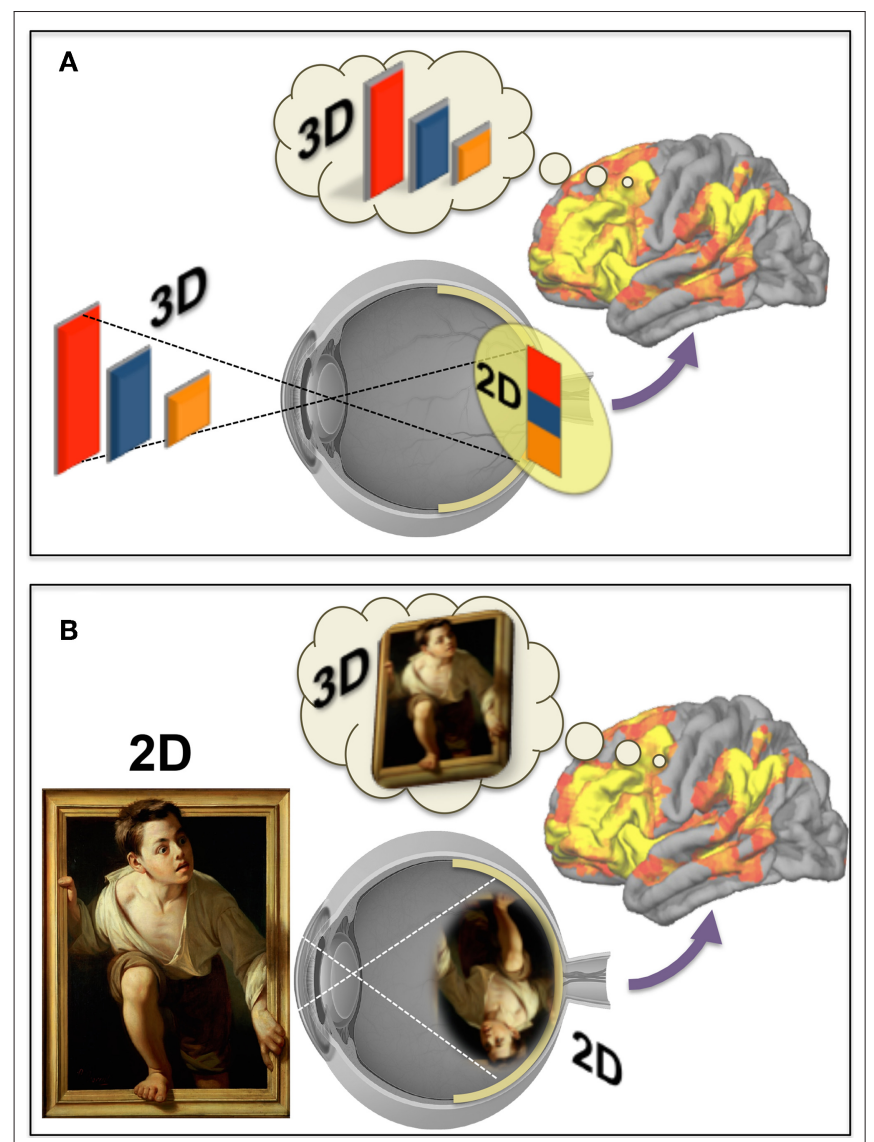

FIGURE 2 | The construction of space. The problem of the brain is to reconstruct 3-D from a flat projection (A), and the problem of painters is to represent 3-D on a flat surface $(\mathbf{B})$. The picture is "Escaping from the critic" by Pere Borell (1835-1910), Colección Banco de España, Madrid. extensively Kandel (2012, 2016), Zeki (1997, 1999), Livingstone (2002), Conway and Livingstone (2007), Changeux (2012) or Ramachandran and Hirstein (1999) to cite only few of the pioneering neuroscientists who explored this field. Their views converge well with art scholars who investigated the psychology of art perception like Gombrich (1950) and Gombrich (1960).

Besides portraying beauty, art has been created to intimidate, to teach, to express sorrow, to make us think, to distract, among many other functions. These multiple meanings respond to the most diverse cultural backgrounds and moments in history, and probably they make the most interesting aspect of art. We do not address here the question of creativity (Dietrich and Haider (2017), but the neurological scaffold of art perception. For example, the shift to a naturalistic representation of the divinity during the Renaissance responds to a theological program, but it involves a technical problem. Its solution is based on the use of perspective and the understanding of the rules of perception. And there is no other way to create an illusion of three dimensions if not following the rules used by the brain to decode 2-D data. Therefore, the later act as a constraint to the former. We deal with what is in art "before" meaning. Neurosciences have little to say about meaning or to the cultural diversity inherent to art. However, biology may clarify the rules on which the artistic work is based, the so-called "perceptual grammar of art": "Artists do the discoveries, and we figure out why those tricks work" (Cavanagh, 2005).

The discussion starts with the following question: "if beauty is in the eye of the beholder, what is in the beholder's eye?" When recapitulating the rules of perception, artists appear as intuitive neuroscientists, they explore the brain "to reach our soul." We review the several "tricks" used by great painters to hit our perception, to create illusions that allow convincible meaning. Foveal vs. peripheral vision, color and movement processing, the dynamic range of face cells in the IT cortex, the discussion on space perception. Further, the value of symmetry in art and in biology, the concept of peak-shift or the biological value of extreme features are discussed (Ramachandran and Hirstein, 1999). Super-stimulus are those that go beyond the range of natural stimuli and they are particularly efficient in art. Think of a caricature or Picasso's portraits or the Guernica. This is particularly interesting because we know that "face cells" in the IT cortex do respond also to extreme features, suggesting that our brain has a safeguard to identify categories that "may exist" beyond natural objects. And of course this is a tool for artists to explore the boundaries of our perceptual systems. Beyond the anecdote of explaining this or that particular technique or artistic success, it is interesting to explore the notion of "perceptual grammar" as the set of rules that precede meaning. An we discuss here the idea that art is subjective, but not arbitrary. Art needs to vibrate with the rules of perception (rules of beauty?) even if the artist wants to show that he is not following them. One interesting discussion here is whether there are limits for that game, and whether breaking the rules, say cubism or atonal music are "neurological fiascos" (see below). Some food for a general discussion on aesthetic universals, and on philosophical thinking on beauty.

\section{The Little Artwork Project}

After going through "the grammar of art," the students are called to produce a "Little Artwork project," a way of exploring the neuroscience behind their own experience of beauty. This is a very engaging activity inspired in the work of Jean Hertzberg (University of Colorado Boulder) who runs a fascinating course on "Art and physics of flow" (see https://www.colorado.edu/ mechanical/flowvis). The task of the students is to produce something that they consider "beautiful" or "aesthetically pleasing," generally a photograph or a painting or a collage for those with some expertise. The work can start from the rules or more frequently from intuition, to then analyze which are the rules that were unconsciously followed in the picture. Works are collectively analyzed, the question being: Where is beauty in the picture? Why is it appealing? Which are the rules present? Which are subverted? We analyze how categorization, perspective, monocular space cues, symmetry, color or extreme features are used or emphasized, and how they build up a particular gesture in the artwork. We also confront the class analysis with the author's own view and intentions. Some examples of these student's works are shown in Figure 3. 

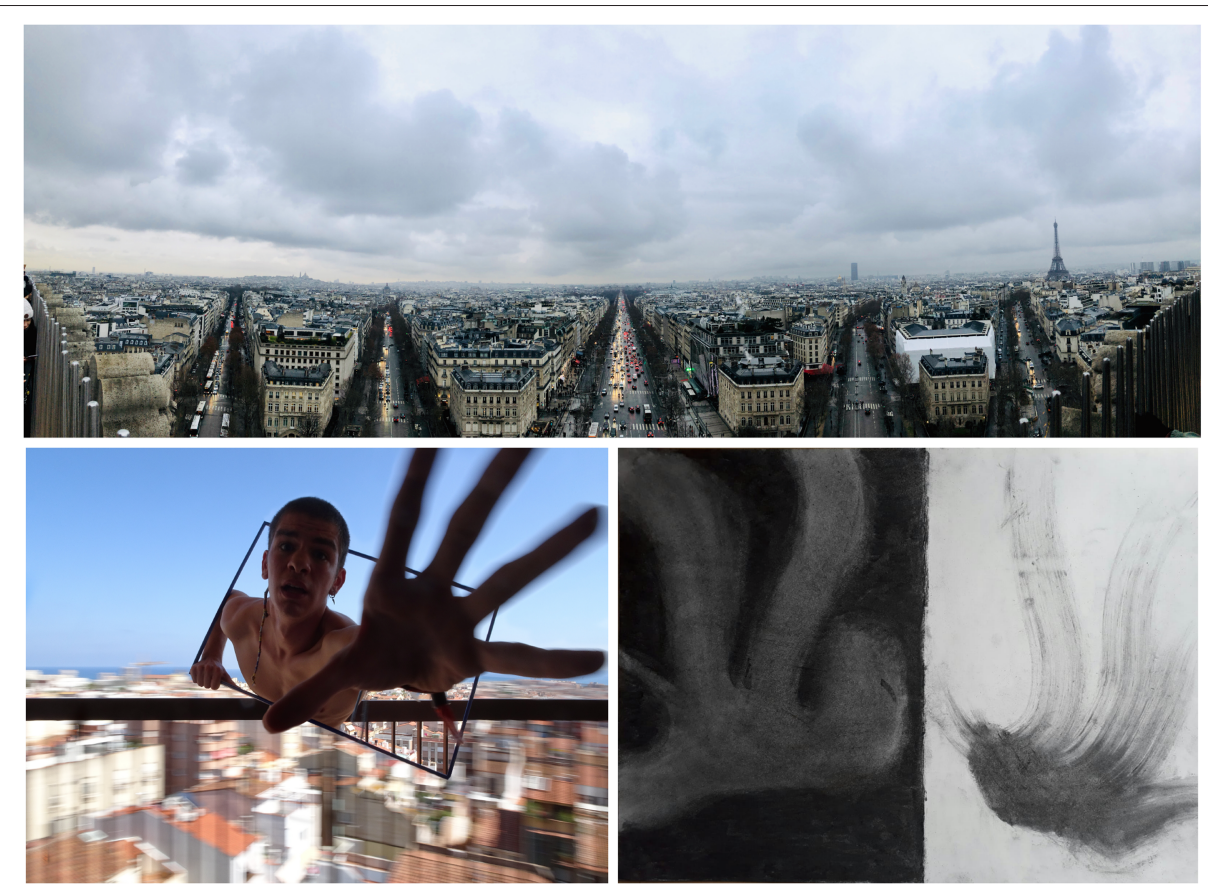

FIGURE 3 | Little artworks. Student's photographs analyzed in the class. Upper: "Paris" (James Dunlea, USA, 2019). The photograph has paradoxical vanishing lines corresponding to multiple viewpoints with strong perspectival cues. A mixed sense of reality and the impossible. It also generates various symmetry axes and plays with object categorization. Lower left: "Take me out" (Oriol Buscà, Barcelona 2018). This is a composition where foveal/peripheral vision is exploited, along with a strong foreshadowing which gives a particular sense of depth and movement. Lower right: Elisabet Besearan, Barcelona 2019 , who plays only with luminance forcing peripheral vision. It appeals for abstract object recognition and for both simple and false symmetry. Oriol Buscà has given the written informed consent to appear in this figure.

\section{Hearing and Music}

"As neither the enjoyment nor the capacity of producing musical notes are faculties of the least direct use to man in reference to his ordinary habits of life, they must be ranked among the most mysterious with which he is endowed" Darwin, The Descent of Man.

We review here the basic mechanisms of hearing, from mechano-transduction to object recognition and space localization. The auditory pathway is another beautiful example of the "deconstruction" of external complexity and its reconstruction by the brain, according to internal principles. General principles for audition are similar to vision, categorization being one major function of hearing (Heald et al., 2017). Bat physiology has produced beautiful work that helps to understand the neural processing of auditory information. Cortical organization of the auditory pathway in bats show how object identity, speed and acceleration can be mapped to the brain (what is "water" for a bat? in https://www.youtube.com/ watch? $\mathrm{v}=\mathrm{gZxLUNHEmPw}$ ). Sound localization in owls is also a beautiful example of how synaptic organization generates a description of the external space from interaural differences. This sets the ground to discuss music and the brain.

Music is universal, in the sense that it appears in every human culture (Peretz, 2006; Koelsch, 2011). Quite mysterious, because as in the above quote of Darwin, its "adaptative value" is not at all clear. However, its material existence as sequences of sounds makes scientists ask about how biology conditions both its production and its reception. And at this stage of the course students may guess that some answers come from the structure and rules of our perception. We first examine pitch as a major component of music, both as melody or harmony. Pitch is somehow mysterious, because on one hand, it has a direct correspondence with the frequency of the sound waves, the higher the frequency the higher the pitch. But on the other hand, it becomes the same when the frequency is doubled! Therefore, it cannot be mapped to a particular frequency but to a relationship between frequencies. Pitch comes from periodic waves (aperiodic waves are perceived as noise) and is a value or a quality that is generated by our brain, and not a property of the sound waves, very much like color in the visual system. The adaptative value of pitch is straight: mostly (if not only) animals are able to generate periodic waves and pitch is essential for auditory object recognition. Brain imaging and, more directly, electrophysiological recordings have identified pitch specialized cortical neurons in marmosets that respond in an invariant manner to sounds that have the same pitch but vary in their harmonic composition, and not to single frequencies (Wang, 2013).

Why music is made in intervals and scales? Humans can discriminate more than 200 intervals in an octave, but we separate scales in a much fewer number of intervals, that we call tones and semitones. Even considering only the seven intervals of 
the natural notes A-G, there are thousands of ways of organizing them in scales. Examples of scales are pentatonic and heptatonic scales, and most of the known scales are variations on them. There are many studies on this topic, but Dale Purves has provided an interesting insight on the origin of scales and tonalities, suggesting that the basic structure of scales depends on common features of language related to our vocal tract. On the other hand, he proposes that that the aesthetic preferences for particular scales may depend on the harmonic properties of language (Bowling and Purves, 2015; Purves, 2017). Another constraint for using a short number of notes is likely the limitation of the working memory. For instance, Trehub et al. (1999) coined the term "unequal interval principle": consonance is obtained with jumps of several semitones in Western music and provides the listener with the sensation of location, tensionresolution, and is accessible to working memory. In summary, the principle we discuss in this part is that the ubiquity of scales may be related to the rules of perceptual processing.

Further along this line, we may ask: why sopranos and tenors are so thrilling? Or why electrical guitar solos are in the high pitch? We don't know, but if we search in our brain, we find that high frequencies are far more represented and discriminated in our brain than medium or low frequencies (Trainor et al., 2014). Both of them use shifts in frequency along with increasing volume. Crescendos and glissandi are typical resources not only for singers, but also for the violin and the guitar, for example. In biological terms, those are no other than looming sounds, approaching sounds that are ecologically relevant and actually "enlarge" the visual response (Hall and Moore, 2003). This is an opportunity to discuss briefly multimodal neurons that integrate sound and visual response and make "see bigger what sounds upward" (see Sutherland et al., 2014).

Finally, we discuss the well-know idea of music as an exercise of anticipation (Levitin, 2007). One main function of our sensory systems is to predict (Llinás, 2002), and this is one main asset for music. In analogy to the above discussion on art, we may regard scales, tonalities, looming sounds etc. as elements of our "perceptual grammar for music." However, expectation of what is coming next is out of the reach of painting, but a weapon of mass destruction in the hands of musicians. Like with vision (or language or taste), we develop different sets of perceptual templates to the extent that we have been exposed to different environments, musical systems in our case. The way melodic or rhythmic expectations are treated is one essential part of music. Here I call students to listen to fragments of classical music (this is part of the educational plan), or play some classical guitar to illustrate some of the above. For instance, deceptive cadences in Satie, or unexpected beats like those present in flamenco or Latin-American rhythms. It is interesting here to ask students to bring their instruments to the class. This normally works well with flute, violin or guitar, sometimes attempting a little duet. Musically educated and knowledgeable students bring interesting examples of polyrhythms or particular cadences from classical, pop, or rock music.

Again, the concept of a "perceptual grammar" of art is discussed here as a constraint for musical composition as it is for vision. I like to propose here a general discussion on art and rules. Whether there is art without rules, and why some attempts to get rid of them loose the intuitive connection with audience, whether or not they are a "neurological fiasco." Pierre Boulez, a contemporary musician and champion of atonal music, serialism and other renovating currents of the twentieth century acknowledged in an interview in 1999 that: "Maybe we did not have enough in account the way in which the music is perceived by the listener (quoted by Trainor, 2008)". Which is an interesting reflection on the brain capacity of creation of objects/forms that are then incapable of solving. "Every innovation, each musical novelty must pass through the transmission screen intergenerational, it must pass through the filter of the brain (Trehub, 2015)."

\section{Into Philosophy: Perception and the Question of Knowledge}

"To them, I said, the truth would be literally nothing but the shadows of the images" Plato "The allegory of the cave."

In this block the discussion is addressed to some major philosophical questions emerging from the analysis of perception. The neuroscience of vision and hearing shows well the distance between "things and ourselves" and this invites revisiting the writings of great philosophers of the past who addressed this question. We return here to Plato's Allegory of the Cave and open three questions: (1) The so called mind body problem, the discussion of dualism and monism. (2) What is the relationship between our perceptions and the world? the question of idealism vs. realism (and its variants), and (3) Which is the origin of our knowledge, rationalism vs. empiricism and the tabula rasa, which links to the more general question of nature and nurture.

On monism and dualism it is interesting to open a short discussion. One strategy here is to make monists find the problems in monist position and dualist in dualism (this is interesting because generally students get completely blocked in discussing their own beliefs, see below). Along this line, it is also interesting to confront the classical text of Descartes (1641) in "Meditations VII" with the blunt and harsh monist declaration by Crick in the "Astonishing Hypothesis" (Crick, 1995). Those are just examples to provide a hint on the nature of the discussion, which attracts legions of philosophers and scientists who meet in international meetings. I rather like to limit this discussion and step into the next question, which I find generally more productive.

Philosophers and natural philosophers (scientists) of the Enlightenment where particularly concerned about the problem of how we ground knowledge, something that therein became one -if not the major question in modern philosophy. Of course, the physiology of the senses has brought good a deal of understanding about the nature of our interaction with the world and of our perceptions -one student of philosophy attending the course once told me that this was not a class of neuroscience, but epistemology. The idea here is to read excerpts from Plato, Ockam, Descartes, Locke and Berkeley, who stated the problem of knowledge, to end with Kant's: "we cannot to have knowledge of objects as things on themselves, but only as they are subject of our sensitive intuition, that is, as phenomena" 
(Kant, 1781). One exercise is to read one of these texts and see how much neuroscientific intuitions are in there, or ask what would you tell Descartes if you were able to speak to him today? We compare those texts with others by Kandel, Damasio, Llinás, or Purves, in which they address the same question. Students need to analyze sentences like "We are stuck with the problem of apprehending the physical world and evolution has circumvented it, got around by making the world not according to physics but to its reproductive success" (Purves et al., 2014).

"There is nothing more deceiving that the obvious" Arthur Connan Doyle.

The discussion on the limits of knowledge has led to the commonly accepted philosophical position that we can only make conjectures, models of reality that we can handle, "to reduce the goals of Science, giving up the search for the understanding of the world in favor of something weaker: theories that are intelligible for us" (Chomsky, 2017). Science is a highly formalized way of making models, however, we live everyday with models that far from being based on science they are based on our own experience, something that has deep evolutionary roots: "A creature must employ a strategy or at least rely on certain rules about the outer world in which it moves, otherwise the movement would be useless or dangerous for its survival. The organism has to anticipate the result of its movement from its sensory organs" (Llinás, 2002). This brings out the fundamental discussion on the differences between science and belief, which we address from the knowledge of the neuroscience of perception.

Our daily behavior requires a strong aprioristic way of interpreting the world, which relies on the innumerable assumptions and implicit knowledge we acquire along our lives. Those models are based on our perceptions and cannot go further than our own experience. A good example is the discussion by Wittgenstein on the limits of out intuition using the question of what would be the effect of increasing one yard an imaginary rope circling the equator? (see the recent post by the Center for Public Philosophy, 2019). Our perception and our experience are the path to belief, a rather timely problem in today's world. "The basic fallacy, taking precedence over all specific metaphysical fallacies, is to interpret meaning in the model of truth" (Arendt, 1981). I also like to bring here the ideas of Robert Burton on "certainty as a feeling," in his words "the brain has developed a constellation of mental sensations that feel like thoughts but aren't. These involuntary and uncontrollable feelings are the mind's sensations; as sensations they are subject to a wide variety of perceptual illusions common to all sensory systems" https:// www.salon.com/2008/02/29/certainty/.

The next question is then: what is science, and in what it differs from common belief? because science must be also a conjecture, a model of reality. We examine here some of the characteristics of the scientific practice and rules, like that it is based on inter-subjective assessment, it looks for local truths, it develops tools that go beyond our senses what makes it frequently mind-bending and counterintuitive. The notion that science is commonly challenging the obvious, something reminiscent of return of the prisoner to the cave: "would he not be ridiculous? Men would say of him that up he went and down he came without his eyes; and that it was better not even to think of ascending; and if any one tried to loose another and lead him up to the light, let them only catch the offender, and they would put him to death" (Plato, Republic VII, in the Allegory of the Cave). In this part, texts by Russell, Chomsky or Hanna Arednt are excellent material for discussion and further frame questions on science and belief, religion, pseudoscience or post-truth, which normally come up in the discussions.

\section{Genes and Culture}

"...it has no sense to demand whether the inclination of Romeo for Juliette was cultural or genetic.... The brain structures that allow those neural operations mature and organize thanks to the constant interaction between the biology and the environment during child's development" (Jacob, 1970). The possible and the actual (La logique du vivant).

To finish the course, we open a general discussion on "genes and culture," nature and nurture. This is a problem that is full of misconceptions and traditional beliefs for the general public, and students-even science students-do not escape from them. The goal is to provide a good frame to the question and to show its complexity. I like to identify first the ideological, religious and political prejudices around this topic. One exercise is to call the class for "spontaneous associations" after the words "innate" and "acquired." The list goes like innate, heredity, genetic, fixed determined, eugenics, social Darwinism, social inequality, racism, sexism, discrimination. And for acquired are non-hereditary, environmental, social, cultural, modifiable, not determined, the "good savage," egalitarianism, fairness, antiracism, anti-sexism, etc. It is not rare to see in the press alignments like conservatives being pro-genetic and liberal and left intellectuals being anti-genetic, as if genetics would justify inequalities or undermine the chances of social transformation. Secondly, to understand the generation of individual perceptual systems is necessary to discuss the complexity of the interactions between genes and environment occurring throughout life, bringing up the concept of gene expression, gene regulation and multigenic factors. The notion of "the gene for music," or "the gene of intelligence" is far more extended than expected, and we need to debunk that as we did with the notion of "the center of music," "the center of love..." (see Moore and Shenk, 2017). The brain is not a green pea and complex features and brain functions like intelligence, character or musical ability depend on the expression of many genes, they are multigenic. There is no such thing as "the gene of something." Further, it is important to discuss the probabilistic nature of the relationship between genotype and phenotype, where environmental interactions and chance play a fundamental role, At this point, it is also interesting to bring up the discussion and distinction between mechanisms and causes: the underlying mechanisms of behavior or disease is always biological: genes, cells and interactions, "the brain is the final common pathway, the conduit that mediates the influences of all the distal factors" (Sapolsky, 2017). The "cause"-whatever this word may mean-of a particular phenotype arises from complex interactions along time between of genes, environment and chance, "it is impossible to conclude that a behavior is caused by a gene, a hormone, a childhood trauma, because the second 
you invoke one type of explanation, you are de facto invoking them all (Sapolsky, 2017)."

"Understanding the acquired demands an analysis of epigenetic control of synaptic development" (Changeux, 2012). Embryonic development is strongly deterministic and depends on genetic networks deployed during embryonic life. However, in their seminal discovery of "critical periods," Hubel and Wiesel showed that, in mammals, early post-natal life is critical for brain development. Critical periods are discussed in detail to show that the architecture of the brain continues its development after birth and that this depends on its interaction with the environment. The border between innate and acquired gets blurred, and the equivalence of genetic and innate looses weight. And on the other side of the coin, critical periods set individual and social patterns. Such acquired features and traits are not inherited, but adhere to individuals for generations as much as if they were inherited. This notion that highlights the weight of environment to the first plane -and that has some reminiscence to Jung's archetypes- has been claimed by a Jacobin biologist like Richard Dawkins: "We need a name for the new replicator, a noun that entails the idea of a cultural transmission unit, or a unit of imitation. "Mimeme" is derived from an appropriate Greek root... I hope my classicist friends forgive me if I abbreviate mimeme and leave it in meme" (Dawkins, 1976). In summary, heredity goes beyond the genes. In words of Changeux (2012) "Paradoxically, we can say that culture is first and foremost a biological, or rather neurobiological, track. So there is no conflict between nature and culture (Changeux, 2012)".

\section{Chalk Talks}

During the last 2 weeks of the term, students make a presentation in the form of a "chalk talk," meaning no equipment support. Presentations are performed before their classmates. Every student selects a topic from a proposed list (Supplementary Material 4), or they may propose their own, provided that is related to the subjects of the course. Topic selection is on the basis of first to come, first served and the activity includes a one-page abstract of no more than one page, a 10-min talk, with 5-10 min for discussion. Evaluation is done on the abstract, the presentation and the quality of the answers to the questions. I also call two students to question as part of their participation mark. The students who ask are told immediately before the talk, so they have to improvise the question along the talk. The activity implies exposing ideas as well as reacting by putting a "clever question" on whatever topic.

\section{A Word on Teaching Methods}

The course is somehow low-tech in methodological innovations, but nevertheless strongly inspired in active learning (see Slavich and Zimbardo, 2012; Waldrop, 2015). Actual lectures are aimed to take $>30 \%$ of the total credits, some of them being a wrapping up ideas after an oriented but open discussion. As a principle, there are no more than 18 slides per session and there is a final summary of the " 10 things you need to know" for every session. There are always "guest talks" given by colleagues from the Humanities department, on topics related to the course, like philosophical views on aesthetics, theory of knowledge or language, for example. Students have always a pdf version of the slides, where concepts, links and references are presented in an ordered manner. There are several "flipped-class" sessions, where students have to read something or search about a topic to be then discussed in the class (Klymkowsky, 2007). This requires always some sort of guided discussion with main questions to answer or to confront.

Seminars are based on concept/principle definitions, T/F questions and little problems like "why a photograph changes color depending on the light and our vision does not?" We go out and take a photograph to one of us outside, under sunlight, and another one inside under artificial illumination, and discuss the difference. To illustrate principles of sound and music perception, it is fun to bring an instrument. Classical guitar is very easy and useful to illustrate some basic principles and students are invited to do some music in the class. It is not uncommon to have more than one playing the flute or violin.

Regular quiz tests are useful and regularly done as cooperative exams (Rieger and Heiner, 2014). This is indeed a wonderful way of studying and foster interaction among students. The "Little Artwork Project" mentioned above is one off the "highs" in the class and is developed by extracting rules and confronting intentions with results and ideas of beauty. Finally, the "chalk talk" presentations provide a rather wide field for topics that generate interesting discussion. The major problem here is to keep the link between the topics addressed and the science we have to deal with them, and to prevent belief coming before science. This is also an exercise on itself, when students realize that, spontaneously, they may address scientific questions with their current beliefs rather than with what they have just learnt in the class about how the brain works.

\section{CONCLUDING REMARKS}

Liberal arts students find here a scientific approach to the mind that goes beyond metaphorical descriptions. They see also the complexity of understanding the basis of thinking or behavior. And they find also that many philosophical and social questions are scientifically relevant, and that they have a level of understanding -a level of explanation in the biology of the brain. The goal of the course is to show that Neuroscience does not provide the solution, but it sets the constraints for a reasonable view of human behavior and the human condition. In my experience, undergrad students of biomedical sciences, psychology, or neuroscience have a poor understanding of brain physiology, and they are surprised to face the complexity of vision or audition, for example. Also, some of their views on perception come rather from "common knowledge" than from the understanding of how sensory systems work. Some of them encounter for the first time with the "Molyneux problem" or they question themselves with their own "extra-scientific" knowledge a problem like nature and nurture. On the other hand, they are curious to learn about art and philosophy. Students of natural sciences or engineering find here the value of scientific knowledge, that their science 
goes beyond cloning and that their knowledge goes beyond technology. And both science and liberal arts students find an opportunity to approach culture with another view, with another eyes.

In summary, the course brings neuroscience to the field of cultural discussion, it invites to think about "what kind of creatures we are," to exercise the knowledge of the brain, on ourselves, and the others. Further, it wants to stimulate curiosity and interest for classical philosophy, art, and music, it is a way of looking at highbrow culture from another perspective. To teach neuroscience as a liberal art is to discuss science as knowledge, to discuss about ideas and to think about universal questions.

\section{ETHICS STATEMENT}

Written informed consent was obtained from the individual(s) for the publication of any potentially identifiable images or data included in this article.

\section{AUTHOR CONTRIBUTIONS}

The author confirms being the sole contributor of this work and has approved it for publication.

\section{REFERENCES}

Arendt, H. (1981). The Life of the Mind: The Groundbreaking Investigation on How We Think, ed M. McCarthy. New York, NY: Harcourt Brace Jovanovich.

Bowling, D. L., and Purves, D. (2015). A biological rationale for musical consonance. Proc. Natl. Acad. Sci. U.S.A. 112, 11155-11160. doi: $10.1073 /$ pnas.1505768112

Cavanagh, P. (2005). The artist as neuroscientist. Nature 434, 301-307. doi: $10.1038 / 434301$ a

Center for Public Philosophy (2019). Aeon Video. Available online at: https://www. youtube.com/watch?v=gigEFym_iM4

Changeux, J. P. (2012). The Good, the True, and the Beautiful: A Neuronal Approach. Yale University Press.

Chomsky, N. (2017). What Kind of Creatures Are We. Columbia. New York, NY: Columbia University Press.

Conway, B. R., and Livingstone, M. S. (2007). Perspectives on science and art. Curr Opin Neurobiol. 17, 1-7. doi: 10.1016/j.conb.2007.07.010

Crick, F. (1995). The Astonishing Hypothesis: The Scientific Search For The Soul. New York, NY: Simon and Schuster, 1995.

Dawkins, R. (1976). The Selfish Gene. Oxford: Oxford University Press.

Descartes, R. (1641). Meditations Cambridge Texts in the History of Philosophy, 2nd Edn. Cambridge: Cambridge University Press (1996)

Dietrich, A., and Haider, H. (2017). A neurocognitive framework for human creative thought. Front. Psychol. 7:2078. doi: 10.3389/fpsyg.2016.02078

Gombrich, E. (1950). The Story of Art, Revised Edn 2013. London: Phaidon.

Gombrich, E. (1960). Art and Illusion. A Study in the Psychology of Pictorial Representation. London: Phaidon, Princeton University Press (Millennium edition with a preface by the author 2000).

Hall, D. A., and Moore, D. R. (2003). Auditory neuroscience: the salience of looming sounds. Curr. Biol. 13, R91-3. doi: 10.1016/S0960-9822(03)00034-4

Heald, S. L. M., Van Hedger, S. C., and Nusbaum, H. C. (2017). Perceptual plasticity for auditory object recognition. Front. Psychol. 8:781. doi: 10.3389/fpsyg.2017.00781

Jacob, F. (1970). La logique du vivant, une histoire de l'héredité. ÉditionsGallimard. English translation. Thepossible and the actual, Pantheon

\section{FUNDING}

This work was supported by the Universitat Pompeu Fabra and and Programa María de Maeztu MINECO (MDM-2014-0370).

\section{ACKNOWLEDGMENTS}

Thanks to Chus Nieto (Madrid) and Domingos Henrique (Lisbon) for reading the manuscript and inspiring comments. Thanks also to James Dunlea, Elisabet Beasaran, and Oriol Buscà for sharing their photographs. Thanks to all my students of the HESP program and the Neuroscience course of the Universitat Pompeu Fabra.

\section{SUPPLEMENTARY MATERIAL}

The Supplementary Material for this article can be found online at: https://www.frontiersin.org/articles/10.3389/feduc. 2019.00158/full\#supplementary-material

Supplementary Material 1 | First day questionnaire.

Supplementary Material 2 | Course syllabus.

Supplementary Material 3 | Artwork used in the course.

Supplementary Material 4 | List of chalk-talk topics.

Kandel, E. (2012). The Age of Insight: The Quest to Understand the Unconscious in Art, Mind, and Brain, fromVienna 1900 to the Present. New York, NY: Random House.

Kandel, E. (2016). Reductionism in Art and BrainScience: BridgingtheTwo Cultures. New York, NY: Columbia University Press. doi: 10.7312/kand17962

Kandel, E., Schwartz, J., Jessell, T., Siegelbaum, S., and Hudspeth, A. J. (2012). Principles of Neural Science. New York, NY: McGraw-Hill Education.

Kant, I. (1781). The Critique of Pure Reason. London: Penguin Classics.

Klymkowsky, M. W. (2007). Teaching without a textbook: strategies to focus learning on fundamental concepts and scientific process. CBE Life Sci. Educ. 6, 190-193. doi: 10.1187/cbe.07-06-0038

Koelsch, S. (2011). Toward a neural basis of music perception - a review and updated model. Front. Psychol. 2:110. doi: 10.3389/fpsyg.2011.00110

Levitin, D. J. (2007). This Is Your Brain on Music: The Science of a Human Obsession. New York, NY: Penguin LCC US.

Livingstone, M. (2002). Vision and Art. The Biology of Seeing (2002). New York, NY: Abrahams Inc.

Livingstone, M. S. (2000). Is it warm? is it real? Or just low spatial frequency? Science 290:1299. doi: 10.1126/science.290.5495.1299b

Livingstone, M. S., and Conway (2005). Was rembrandt stereoblind? N. Engl. J. Med. 352, 631-632. doi: 10.1056/NEJM200502103520622

Llinás, R. (2002). I of the Vortex: FromNeurons to Self. Cambridge, MA: MIT Press.

Moore, D. S., and Shenk, D. (2017). The heritability fallacy. Wiley Interdiscip. Rev. Cogn. Sci. 8:e1400. doi: 10.1002/wcs.1400

Newman, R. (2017). Neuropolis. A Brain Science Survival Guide. New York, NY: Harper Collins.

Peretz, I. (2006). The nature of music from a biological perspective. Cognition 100, 1-32. doi: 10.1016/j.cognition.2005.11.004

Purves, D. (2017). Music as Biology. Cambridge, MA: Harvard University Press. doi: $10.4159 / 9780674972988$

Purves, D., Monson, B. B., Sundararajan, J., and Wojtach, W. T. (2014). How biological vision succeeds in the physical world. PNAS 111, 4750-4755. doi: 10.1073/pnas.1311309111

Ramachandran, V. S., and Hirstein, W. (1999). The science of art a neurological theory of aesthetic experience. J Consciousness Studies. 6, 15-51. 
Rieger, G. W., and Heiner, C. E. (2014). Examinations that support collaborative learning: the students' perspective. J. College Sci. Teaching 43, 41-47. doi: 10.2505/4/jcst14_043_04_41

Sapolsky, R. M. (2017). Behave: The Biology of Humans at Our Best and Worst. New York, NY; London: Penguin.

Sayim, B., and Cavanagh, P. (2011). What line drawings reveal about the visual brain. Front. Hum. Neurosci. 5:118. doi: 10.3389/fnhum.2011.00118

Slavich, G. M., and Zimbardo, P. G. (2012). Transformational teaching: theoretical underpinnings, basic principles, and core methods. Educ. Psychol. Rev. 24, 569-608. doi: 10.1007/s10648-012-9199-6

Sutherland, C. A. M., Thut, G., and Romei, V. (2014). Hearing brighter: changing in-depth visual perception through looming sounds. Cognition 132, 312-323. doi: 10.1016/j.cognition.2014.04.011

Trainor, L. (2008). The neural roots of music. Nature 453, 598-599. doi: $10.1038 / 453598$ a

Trainor, L. J., Marie, C., Bruce, I. C., and Bidelman, G. M. (2014). Explaining the high voice superiority effect in polyphonic music: evidence from cortical evoked potentials and peripheral auditory models. Hear Res. 308, 60-70. doi: 10.1016/j.heares.2013.07.014

Trehub, S. E. (2015). Cross-cultural convergence of musical features. Proc. Natl. Acad. Sci. U.S.A. 112, 8809-8810. doi: 10.1073/pnas.1510724112

Trehub, S. E., Schellenberg, E. G., and Kamenetsky, S. B. (1999). Infants' and adults' perception of scale structure. J. Exp. Psychol. Hum. Percept. Perform. 25, 965-975. doi: 10.1037/0096-1523.25.4.965
Waldrop, M. M. (2015). The science of teaching science. Nature 523, 272-274 doi: $10.1038 / 523272$ a

Wang, X. (2013). The harmonic organization of auditory cortex. Front. Syst. Neurosci. 17:114. doi: 10.3389/fnsys.2013.00114

Wolfe, J. M., Kluender, K. R., Levi, D. M., Bartoshuk, L. M., Herz, R. S., Klatzky, R. L., et al. (2017). Sensation and Perception. New York, NY; Oxford: OUP.

Zeki, S. (1997). "The Wodhull Lecture: visual art and the visual brain," in Proceeding Royal Institution of Great Britain, 29-63. Available online at: http:// www.vislab.ucl.ac.uk/pdf/Woodhull.pdf

Zeki, S. (1999). Inner Vision. An Exploration of Art and Brain. Oxford: OUP.

Zeki, S. (2018). On Perception. You Are Making Reality Up in a Way. I Mean, the Only Reality You Can Experience Is What the Brain Allows You to Experience. Available online at: https://www.whyarewehere.tv/people/semir-zeki/

Conflict of Interest: The author declares that the research was conducted in the absence of any commercial or financial relationships that could be construed as a potential conflict of interest.

Copyright (c) 2020 Giraldez. This is an open-access article distributed under the terms of the Creative Commons Attribution License (CC BY). The use, distribution or reproduction in other forums is permitted, provided the original author(s) and the copyright owner(s) are credited and that the original publication in this journal is cited, in accordance with accepted academic practice. No use, distribution or reproduction is permitted which does not comply with these terms. 